\title{
Insecticide-Treated Nets, the Key Element for Rolling Back Malaria in North-Eastern India: Policy and Practice
}

\author{
Vas Dev*,1 and Aditya P. Dash ${ }^{2}$ \\ ${ }^{1}$ National Institute of Malaria Research (ICMR), Chachal, Guwahati-781 022, Assam, India \\ ${ }^{2}$ National Institute of Malaria Research (ICMR), 22 Sham Nath Marg, Delhi-110 054, India
}

\begin{abstract}
For decades of attempted control using DDT indoor residual spraying and increased allocation of resources, malaria continues to deter the socio-economic development in the north-eastern states of India. Focal disease outbreaks are recurring and all death cases are ascribed to Plasmodium falciparum malaria. As an alternative strategy to DDT, village scale filed trials with insecticide-treated nets (ITNs) were conducted in malaria endemic pocket of Assam during 1988-1990 that were evaluated to be a success story by the Technical Advisory Committee of the National Vector Borne Disease Control Programme of Government of India. Based on the research findings, a pilot project was undertaken under centrally sponsored scheme to assess the operational feasibility and sustainability of this intervention through primary health care services in the northeast sector for which National Institute of Malaria Research of Indian Council of Medical Research served as the nodal agency for technology transfer. Under this scheme, one hundred thousand insecticide-treated nets were distributed gratis beginning 1996 in communities living below poverty line that were identified by the respective state health directorate of seven states of the northeast. For reporting states of Assam, Meghalaya and Arunachal Pradesh for which data were analyzed, the results were promising in reducing disease transmission, and public response was overwhelming. The communities clearly preferred ITNs against DDT spraying and reported collateral benefits for decreased nuisance due to other household insect pests. Since then provision of ITNs is a continuing activity including impregnation of community-owned nets. We provide data on technology transfer and transmission reduction, and issues related to challenges and prospects for malaria control using ITNs as evidence-based intervention are discussed.
\end{abstract}

Keywords: Malaria, Insecticide-treated nets, north-eastern India, Anopheles minimus, community participation, vector control.

\section{INTRODUCTION}

Malaria is endemic in the northeastern states of India, and transmission is perennial and persistent under the combined influence of Anopheles minimus, An. baimaii (formerly species D of An. dirus) and An. fluviatilis [1]. Plasmodium falciparum is the majority parasite accounting for $>60 \%$ of cases and the remaining are due to $P$. vivax. Focal disease outbreaks are annual events characterized by high morbidity and death cases. For control of malaria, indoor residual spraying of DDT is the mainstay, but this method of vector control is beset with its own operational constraints, viz., high refusal rates ( $>50$ of the households), prohibitive costs, inhospitable terrain etc. Thus, community awareness and participation is now the focus of National Vector Borne Disease Control Programme (NVBDCP) to make malaria control everyone's concern. In this context, communities in this region have been using mosquito nets as personal protection against mosquitoes/ malaria but with varying compliance based on personal preferences. It is proven fact that treatment of these very nets with suitable insecticide, e.g. synthetic pyrethroid increases efficacy manifold as physical barrier between host and the vector mosquito [2].

\footnotetext{
*Address correspondence to this author at the National Institute of Malaria Research (ICMR), Chachal, Guwahati - 781 022, Assam, India; Tel: +91 361 2130934, 2363129; Fax: +91 361 2130920;

E-mail: mrcassam@hotmail.com
}

In India, insecticide-treated nets (ITNs) were first field evaluated against An. minimus transmitted malaria in endemic villages of Kamrup district (Dimoria block) in the Brahamaputra Valley of Assam for the northeast sector [3]. There was $>70 \%$ decline in number of $P$. falciparum cases over 2 year study period with concomitant decline in host vector contact. Much needed community participation was forthcoming so much so that Technical Advisory Committee (TAC) of the National Vector Borne Disease Control Programme decided to launch pilot project study in all seven states of the northeast to test operational feasibility, acceptability and sustainability as an alternative technology for malaria/ vector control [4]. National Institute of Malaria Research (formerly Malaria Research Centre) was identified as the nodal agency for technology transfer to respective State Health Directorate. It has been the objective of this study to present facts of technology transfer in promoting insecticidetreated nets as community driven intervention against malaria in the northeastern states of India. Data were collected to ascertain the impact on disease transmission reduction. The findings of the beneficiary assessment are included, and issues related to challenges and future prospects for vector control are discussed.

\section{TOPOGRAPHY}

The north-eastern region of India $\left(22.4^{0}, 29.31^{0} \mathrm{~N}\right.$; $89.48^{0}, 97.25^{\circ} \mathrm{E}$ ), comprising seven sister states namely Assam, Arunachal Pradesh, Nagaland, Meghalaya, Mizoram, Manipur and Tripura, is of strategic importance having an 
international border with China to the North, Myanmar to the East, Bhutan to the West, and Bangladesh to the South (Fig. 1). It comprises several hill ranges interspersed with valleys that by and large are sparsely populated by number of ethnic tribes characterized by their native languages / dialects, rituals, costumes, and housing patterns. The terrain is difficult and communication means are poor. Many districts of the respective state are located at the foothills / forest fringe/ border areas which are malaria endemic and prone to fulminating outbreaks taking heavy toll on human lives. The primary occupation is paddy cultivation, handlooms and forest produce, and majority populous living under low socioeconomic conditions. Most areas get heavy rainfall (2 meters or above); much of it occurs during monsoon season (July September) with pre-monsoon showers beginning March/ April. The relative humidity varies from $60-80 \%$, and most part of the year is hot and humid $\left(22-33^{\circ} \mathrm{C}\right)$ except November to February, which are the winter months (minimum of $10^{\circ} \mathrm{C}$ ). Overall, the environment is conducive for mosquito proliferation, survival and longevity facilitating perennial transmission of malaria.

\section{METHODS}

\section{Technology Transfer}

As per directives of the National Vector Borne Disease Control Programme, daylong training/ demonstrative programmes were conducted for state malariologists of all seven states of the region in coordination with the Regional Director (Health \& Family Welfare) to provide know-how technology on Insecticide Treated Nets (ITNs). The state functionaries were apprised of the procedures for mosquito net impregnation with synthetic pyrethroid for the targets dose of (say @ $25 \mathrm{mg} / \mathrm{square}$ metre for deltamethrin flow). The oral deliberations were supplemented by video film on the subject and relevant literature, i.e., booklets, folders and wall posters for promotion of the concept at the grassroots. Queries were addressed as to nature of chemical, its properties and safety aspects from public health viewpoint. The participants from respective state included state malaria programme officers, entomologists, malaria inspectors and basic health workers. In addition, daylong training programmes were conducted for defence services, public sector (e.g., Oil Refineries, Paper Mills), and private sector, viz, tea garden industry, and for voluntary health organizations (NGOs) active in the region.

Having completed the training component, one hundred thousand mosquito nets along with required amount of synthetic pyrethroid (deltamethrin $2.5 \%$ flow formulation) were provided to the respective State Health Directorate under centrally sponsored scheme of Ministry of Health \& Family Welfare. The state share of nets and insecticide is given in Table 1. Mosquito nets were treated with deltamethrin @ 25 $\mathrm{mg}$ / square metre by state malaria health workers, and distributed gratis through primary health care system beginning January 1996. The beneficiaries included isolated population groups living under below poverty line vulnerable to malaria outbreaks that were identified by the respective state/ district health authorities.

\section{Anti-Malaria Month - Information, Education and Communication (IEC)}

To generate mass awareness at the grassroots for malaria and its prevention, IEC activities were deemed necessary for enhanced community participation and much needed compliance. National Institute of Malaria Research being the nodal agency, special emphasis was placed on development of health education and extension materials for public circulation. Video film "Insecticide impregnated bed nets for ma-

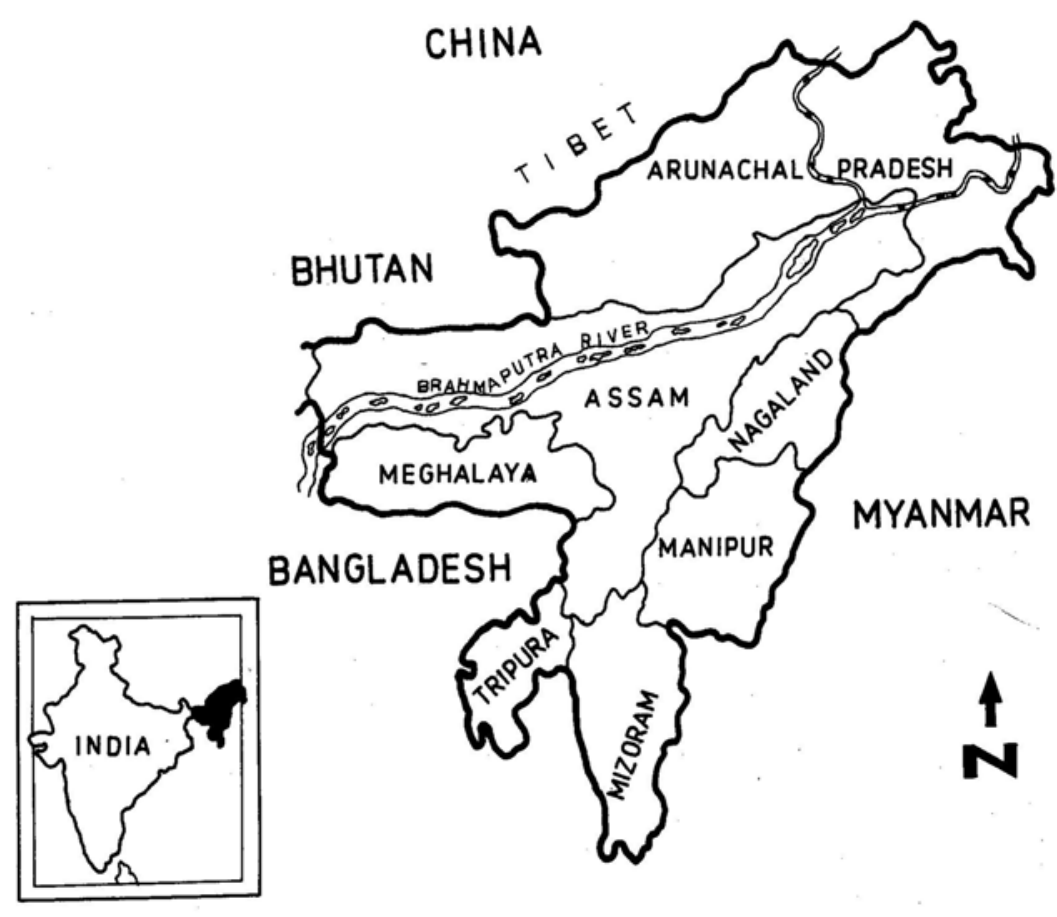

Fig. (1). Map showing geographic location of north-eastern states and international borders with neighboring countries. The inset is the map of India showing north-eastern region. 
Table 1. Technology Transfer of the Insecticide-Treated Nets in the North-Eastern States of India, Share of Mosquito Nets and Insecticide

\begin{tabular}{|c|c|c|c|c|}
\hline State & Nets Distributed & Deltamethrin 2.5\% flow (kg) & $\begin{array}{c}\text { Date of Training } \\
\text { dd-mm-yr }\end{array}$ & Venue \\
\hline \hline Meghalaya & 11,000 & 110 & $21-07-1995$ & Shillong \\
\hline Assam & 24,000 & 240 & $24-07-1995$ & Sonapur \\
\hline Nagaland & 10,000 & 100 & $04-08-1995$ & Sonapur \\
\hline Arunachal Pradesh & 17,500 & 175 & $08-08-1995$ & Itanagar \\
\hline Mizoram & 15,500 & 155 & $13-10-1995$ & Sonapur \\
\hline Tripura & 11,000 & 110 & $13-12-1995$ & Agartala \\
\hline Manipur & 11,000 & 110 & $24-01-1996$ & Imphal \\
\hline
\end{tabular}

laria control" in English, and regional languages, and TV spots on the subject were telecasted by the media supplemented by display of popular articles on the Roll Back Malaria website (www.rbm.who.int). News media were equally exploited to promote ITNs popularly known as 'medicated nets' as personal protection measure. Repeated demonstrations were organized in affected areas in association with NGOs, tea garden industry and district health authorities. Additional training programme were held for state health functionaries annually sponsored under World Bank aided Enhanced Malaria Control Project of National Vector Disease Control Programme. Beginning 1996, other measures included observance of an anti-malaria week in June, and from 1997 onwards the whole month (June of each year) during which programmes on health education / awareness were intensified supported by the media coverage. In addition, training and re-orientation programmes were routinely conducted for all categories of health personnel as capacity building exercises.

\section{RESULTS}

\section{Impact Assessment on Malaria Transmission}

Following distribution of treated nets in January 1996, impact on malaria transmission was monitored by the respective states based on fortnightly domiciliary fever surveillance conducted through primary healthcare services. Based on the data received from the reporting states of Assam, Meghalaya and Arunachal Pradesh, there was drastic reduction in malaria incidence within one year of usage by the communities (Table 2). The declining trends were comparable and convincing among states with diverse landscapes. Seemingly, this intervention was appropriate against malaria transmitting mosquitoes specific to north-eastern India. The results were well received by the programme officials and policy planners to extend the distribution of ITNs in phased manner in communities living under below poverty line with women and children in particular. Since then, provisions are being made annually for additional supply aided by international agencies and donors alike. Not surprisingly, the north-eastern states as a group, what is believed to be hard-core area, showed significant decline in contribution of malaria cases and deaths during last decade (1995-2004) in relation to total disease burden reported in the country (Fig. 2). Observance of anti-malaria month during which health education activities were intensified, training and re-orientation programmes for health workers, partnership with voluntary/ faith based organizations, increased involvement of communities at stake, partnership with public/ private sector, monitoring of high-risk districts by the control programme; all have contributed to appreciable decline in malaria incidences. Media (both regional \& national networks) played a pivotal role for increased awareness by periodic coverage on the subject more so during high transmission season. Based on the re-

Table 2. Impact Assessment of Insecticide-Treated Nets on Malaria Transmission in North-Eastern States of India ${ }^{a}$

\begin{tabular}{|c|c|c|c|c|c|c|}
\hline State & Population & Time Period & $\begin{array}{c}\text { No. Blood-Smears } \\
\text { Examined }\end{array}$ & $\begin{array}{c}\text { No. +ve for } \\
\text { Malaria Parasite }\end{array}$ & $\begin{array}{c}\text { \% of Blood-Smears +ve } \\
\text { for Malaria Parasite }\end{array}$ & $\begin{array}{c}\text { No. of Malaria Cases Per } \\
\text { 1000 Population }\end{array}$ \\
\hline \hline \multirow{2}{*}{ Assam } & 31467 & Jan-Dec 1995 & 12713 & 2215 & 17.41 & 70.39 \\
\cline { 2 - 7 } & 32732 & Jan-Dec 1996 & 2715 & 178 & 6.55 & 13.76 \\
\hline \multirow{2}{*}{\begin{tabular}{c} 
Meghalaya \\
\cline { 2 - 7 }
\end{tabular}} & 8946 & Jan-Dec 1995 & 4424 & 609 & 6.34 & 60.00 \\
\hline \multirow{2}{*}{$\begin{array}{c}\text { Arunachal } \\
\text { Pradesh }\end{array}$} & 9404 & Jan-Dec 1995 & 6431 & 828 & 12.87 & 26.67 \\
\cline { 2 - 7 } & 9710 & Jan-Dec 1996 & 5567 & 86 & 1.54 & 88.05 \\
\hline
\end{tabular}

${ }^{a}$ Source: Data collected by the respective State Health Directorate through primary healthcare services (for other northeastern states, the distribution of nets was irregular and patchy, thus data could not be evaluated). The re-treatment of nets was not conducted as scheduled, thus data of the subsequent years could not be considered.

${ }^{\mathbf{b}}$ Data for January - December 1995 is the baseline malaria incidence. Mosquito nets treated with deltamethrin (2.5\% flow) were introduced in January 1996. 


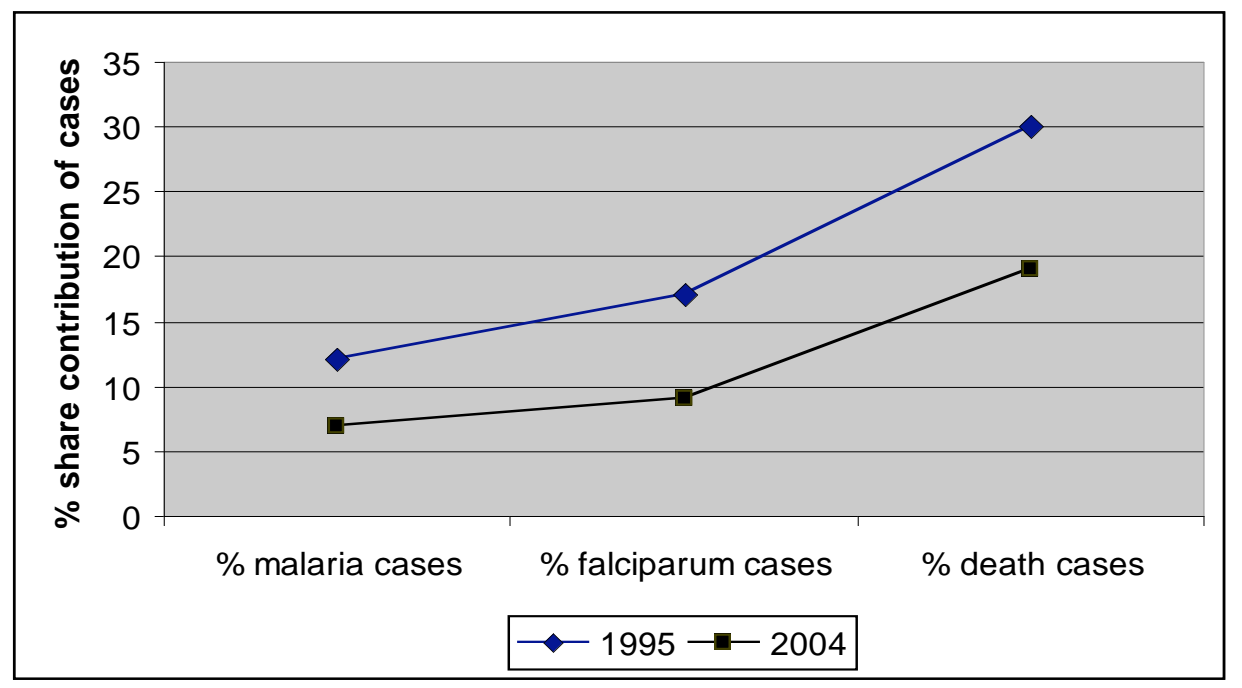

Fig. (2). Per cent share contribution of reported malaria cases and deaths in north-eastern states compared to country's total during 1995 2004 (Source: National Vector Borne Disease Control Programme, Government of India)

Table 3. Summary Results of Mosquito Net Ownership and Usage Based on Cross-Sectional Community Surveys in the Sonapur PHC (Dimoria block), Kamrup District, Assam, India ${ }^{\text {a }}$

\begin{tabular}{|c|c|c|}
\hline S. No. & Parametre & Response \\
\hline 3. & No. $(\%)$ of households with nets & $335(93 \%)$ \\
\hline 4. & Total (\%) population using nets & $1646(83 \%)$ \\
\hline 6. & No. Individuals (\%) without nets in the same houses as people using nets, i.e., subject to diverted mosquitoes & $217(11 \%)$ \\
\hline 7. & No. $(\%)$ households with nets torn & $190(53 \%)$ \\
\hline 8. & Total nets inspected & 950 \\
\hline 9. & Total $(\%)$ nets torn & $374(39 \%)$ \\
\hline \multirow{2}{*}{10.} & $10-20$ years & $167(50 \%)$ \\
\hline & $>20$ years & $161(48 \%)$ \\
\hline 11. & No. $(\%)$ households with nets from donor agencies & $8(2 \%)$ \\
\hline
\end{tabular}

${ }^{a}$ Study period: October/ November 2004.

ported surveys on public perceptions and preferences, the net ownership by the communities was confirmed to be high $(>90 \%)$ and majority were habitual users $(>80 \%)$. Fair proportions of these population groups had some knowledge of ITNs but advocated provision of free supply by the government /donors [5, 6]. A cross-sectional surveys of the community-owned mosquito nets revealed that the number of nets owned by some families were just not enough to the extent that $25 \%$ of the households, and $>50 \%$ of the nets owned were torn. Concurrently, some individuals $(11 \%)$ in the same house were subject to diverted mosquito permitting infective mosquito bites (Table $\mathbf{3}$ ).

\section{The Beneficiary Assessment of ITNs}

To develop recommendations for the National Vector Borne Disease Control Programme in implementing ITNs as alternative strategy in lieu of DDT residual spraying for vector control on the sustainable basis, a central team conducted the beneficiary assessment in November 1996 through a series of questionnaires and personal visits at various levels of malaria control operations. The objectives were: (i) to assess the process of supply, distribution, re-impregnation and utilization of mosquito nets, (ii) to assess information, education and communication activities, (iii) to assess the impact on 
malaria transmission and public perceptions. The salient findings of the committee were as under:

1. There was pronounced impact on malaria transmission by minimizing host/ vector contact.

2. Insecticide-treated nets were preferred over residual DDT spraying for vector control.

3. There was demand for additional supply of these nets by the communities, and the concerned states recommended making provision for families living below poverty line.

4. The committee noted that re-impregnation exercises that were necessary every six months were done poorly or not done as scheduled.

5. There was dearth of monitoring /evaluation exercises, and lack of initiative for health education activities that were vital to the programme.

\section{DISCUSSION}

\section{The Challenges Ahead}

It is amply clear that intervention based on insecticidetreated nets is evidence-based, appropriate and community driven for disease transmission reduction. The transmission trends are seemingly declining, and communities today are increasingly aware of the disease and its prevention. However, the malaria challenge remains undefeated with the emergence of drug-resistant $P$. falciparum malaria, continuing poverty, increased costs of treatment, and decreased productivity. Focal outbreaks of the disease continue to occur, and capacities of the health staffs are diminishing owing to attrition and vacancies at all echelons of field operations lending to fragmented surveillance and poor reporting of cases. True incidence of malaria morbidity and mortality is estimated to be manifold of the reported cases and deaths [7]. Chloroquine resistance is widespread and therapeutic response to alternate therapies is fast declining [8]. Owing to reported recrudescence rates with artemisinin derivatives as monotherapy, there is gradual shift to use of artemisininbased combinations (ACTs) for treatment of drug-resistant cases (several combinations are now in trial for their therapeutic efficacy) that provide rapid cure and obviate development of drug-resistant strains [9 -11]. But treatment costs would be colossal adding to penury of the poverty stricken communities where malaria is major illness. Drug resistant strains are multiplying fast in the northeast sector that is believed to be the corridor for spread to the peninsular India [12]. Almost $30 \%$ of the global population at malaria risk is estimated to be living in the South-East Asia region of the World Health Organization (second only to Sub-Saharan Africa) that is fast becoming the epicenter for spread of multi-drug resistant malaria [13]. The risk of contracting malaria is much greater in border areas of northeastern India where the health infrastructure is meagre or non-existent [14]. These marginalized population groups invariably deprived of equitable access to quality healthcare are caught in perpetuating vicious cycle of poverty, and serve as parasite reservoir facilitating spread of drug-resistant malaria.

As the old saying goes that prevention is better than cure, there is need for scaling up the supply and distribution of ITNs manifold, improve affordability by reducing taxes and tariffs, and promote culture of using ITNs as personal protection measure (see, Report of the second International Conference on Insecticide-treated nets in the $21^{\text {st }}$ Century held in Dar-es-Salaam, Tanzania during 11 -14 October 1999). The success of the ITNs programme rests on the sustained availability of these treated nets and proper use by those most at risk of contracting malaria (Fig. 3). The challenge is to ensure equitable access to quality healthcare for poorest of the poor and high-risk population groups including pregnant women and children to prevent severe malaria and deaths. Innovative strategies are deemed necessary to promote partnership between governments, NGOs, donors, the commercial sector, and above all the communities to meet increasing demand and affordability [15-17]. For scaling up coverage under ITNs, it is vital to prepare roadmaps that should include advocacy, planning and information exchange, mobilization of additional resources, human resource development, and monitoring and evaluation.

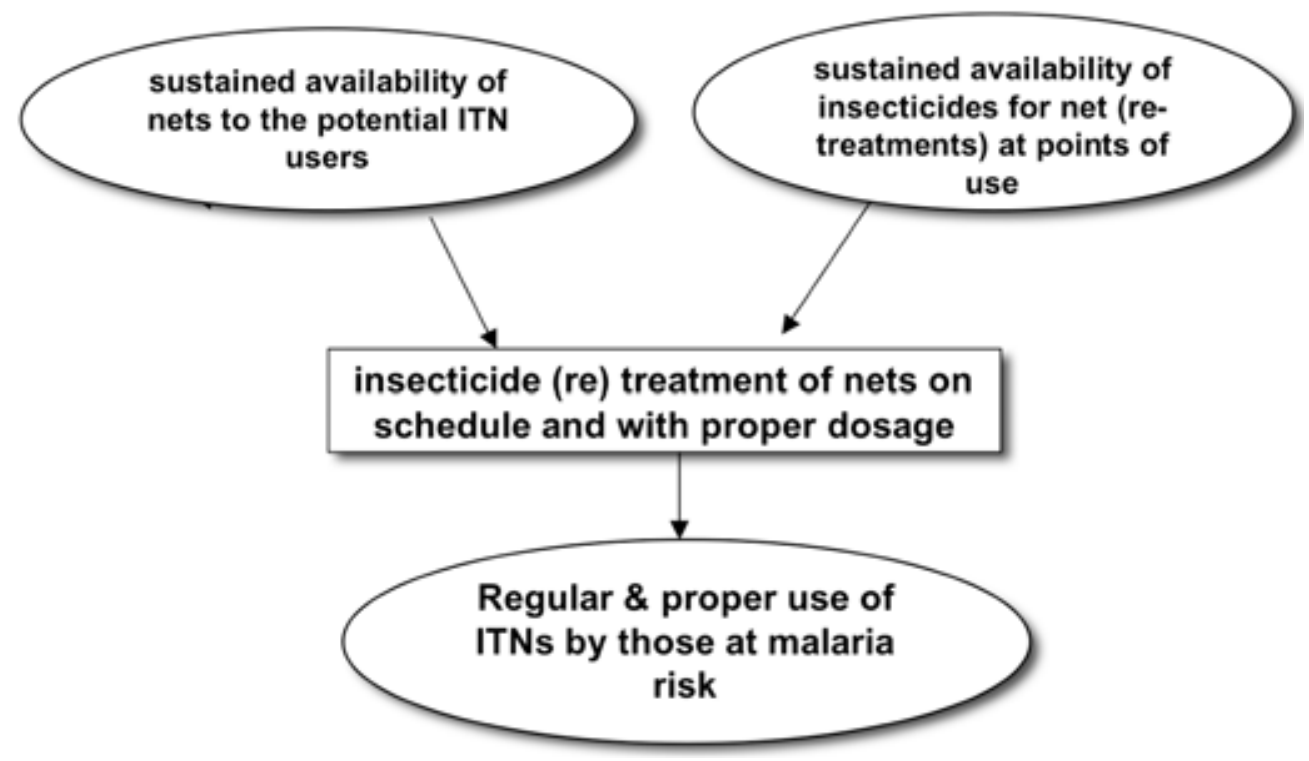

Fig. (3). Flow chart of activities for sustained intervention based on insecticide-treated nets for malaria control. 


\section{FUTURE PROSPECTS}

To ensure equitable socio-economic development, it is imperative to combat the malaria scourge by appropriate policy in place and time for vector control and radical treatment of cases. In face of population explosion and resource crunch, it is equally important to set priorities for effective control on the sustainable basis. It is advocated that interventions should be focused in high-risk areas contributing most cases and deaths, and saving operational costs [14]. Healthcare infrastructure should be strengthened at the periphery where that is needed most for confirmed diagnosis and management of severe malaria [18]. Training and orientation programmes must be a continuing activity in upgrading skills of health workers for accurate diagnosis, case management and reporting for estimating true disease burden. An early warning and better reporting system would help evidence-based targeting of interventions to avert impending disease outbreaks and restoring confidence in resource-poor communities. There being low acceptance to DDT residual spraying, poor quality and coverage, it is need of the hour to consider integrated approaches/ appropriate mix of technologies that are situation specific and are community-based with proven success $[19,20]$. Equally important is to ascertain the susceptibility status of vector population against insecticide in use and monitoring therapeutic efficacy of antimalarial drugs for upgrading treatment policy. The advent of pretreated mosquito nets with insecticides popularly known as long-lasting insecticidal nets (LLINs), e.g., Olyset ${ }^{\circledR}$ nets, PermaNet ${ }^{\circledR}$ that would reduce hassles of treatment especially re-treatment present a good alternative as sustainable intervention method [21]. These are ready-to-use pre-treated wash-resistant nets, which do not require further treatment for 4 - 5 years (the expected life span of net). WHO provides technical information and regular updating on LLINs through RBM website (www.rbm@who.int/ITNs). For scaling up the availability and affordability of these nets, behaviour change communication for greater compliance, publicprivate partnership and strengthening inter-sectoral convergence should all be considered for making the programme a gala success. Preventing malaria would also provide many protective effects on health against other infectious diseases such as HIV; thus full value of LLINs in personal protection can only be realized by wider coverage combined with effective treatment. In disease control operations, community participation should remain the guiding principle for which information, education and communication activities have important role to play to achieve vision of well-informed and self-sustainable healthy India free from vector borne diseases. Long-term malaria control strategy should rely on generation of increased awareness of the disease and its prevention, and international commitment for enhanced allocation of resources for ensuring free supply of antimalarial commodities such as drugs, diagnostic methods, insecticides and mosquito nets for mass distribution to communities at stake. Malaria should be addressed as public health problem in relation to poverty, ecological, social, environmental and developmental changes. We believe that intensification of these interventions in the South-East Asia Region of the World Health Organization (SEARO) would yield rich dividends in achieving millennium development goals by limiting transmission, and saving lives.

\section{ACKNOWLEDGEMENTS}

The authors are grateful to Dr. V.P. Sharma presently at the Centre for Rural Development \& Technology, Indian Institute of Technology, Delhi for valuable inputs and encouragement for field-based operational research to help malaria control programme specific to the north-eastern states of India. We would also like to acknowledge the assistance and cooperation of the Directorate of National Vector Borne Diseases Control Programme, Delhi for making adequate provision for supply of mosquito nets and insecticide, and the Programme Officer of the respective north-eastern states for implementation and monitoring ITNs as an alternative technology. Technical assistance of S. Phookan and other project staffs is acknowledged.

\section{REFERENCES}

[1] Dev V. Anopheles minimus: its bionomics and role in the transmission in malaria in Assam, India. Bull World Health Organ 1996; 74: 61-6.

[2] Curtis CF, Myamba J, Wilkes TJ. Comparison of different insecticides and fabrics for anti-mosquito bednets and curtains. Med Vet Entomol 1996; 10: 1-11.

[3] Jana-Kara BR, Wajihullah WA, Shahi B et al. 1995. Deltamethrin impregnated bed nets against Anopheles minimus transmitted malaria in Assam, India. J Trop Med Hyg 1995; 98: 73-83.

[4] Dev V. Insecticide impregnated mosquito nets: An alternative strategy for malaria control. Curr Sci 1998; $74: 5$.

[5] Dev V. Operational aspects of insecticide treated nets for malaria control in Assam. J Comm Dis 2001; 33: 147-50.

[6] Dev V, Phookan S, Sharma VP, Dash AP, Anand SP. Malaria parasite burden and treatment seeking behavior in ethnic communities of Assam, Northeastern India. J Infect 2006b; 52: 131-39.

[7] WHO. World Malaria Report 2008. Geneva: World Health Organization. Available: http:/www.rbm.who.int/wmr2008 (Accessed 12 October 2008).

[8] Sharma VP. Current scenario of malaria in India. Parassitologia 1999; 41: 349-53.

[9] Asthana OP, Srivastava JS, Kamboj VP, et al. A multicentric study with Arteether in patients of uncomplicated falciparum malaria. J Assoc Phy India (JAPI) 2001; 49: 692-6.

[10] Sharma VP. Malaria and poverty in India. Curr Sci 2003; 84 (4): 513-5.

[11] Sharma VP. Artemisinin drugs in the treatment of Plasmodium falciparum malaria in India. Curr Sci 2006; 90 (10): 1323-1324.

[12] Mittra P, Vinayak S, Chandawat H, et al. Progressive increase in point mutations associated with chloroquine resistance in Plasmodium falciparum isolates from India. J Infect Dis 2006; 193: 130412.

[13] Hay SI, Guerra CA, Tatem AJ, Noor AM, Snow RW. The global distribution and population at risk of malaria: past, present, and future. Lancet Infect Dis 2004; 4: 327-36.

[14] Dev V, Dash AP, Khound K. High-risk areas of malaria and prioritizing interventions in Assam. Curr Sci 2006a; 90: 32-6.

[15] Makemba AM, Winch PJ, Kamazima SR, et al. Community-based sale, distribution and insecticide impregnation of mosquito nets in Bagamoyo district, Tanzania. Health Policy Plan 1995; 10: 50-59.

[16] Morgan LM. Community participation in health: perpetual allure, persistent challenge. Health Policy Plan 2001; 16: 221-30.

[17] Espino Fe, Koops V, Manderson L. Community participation and tropical disease control in resource-poor settings. UNICEF/UNDP/World Bank/WHO Special Programme for Research \& Training in Tropical Diseases 2004; TDR/STR/SEB/ST/04.1, Special Topics No. 2, p. 48.

[18] Winstanley PA. Chemotherapy for Falciparum malaria: The Armoury, the Problems and the Prospects. Parasitol Today 2000; 16: 146-53. 
[19] Shiff C. Integrated approach to malaria control. Clin Microbiol Rev 2002; 15: 278-93.

[20] Curtis C. Insecticide-treated nets against malaria vectors and polystyrene beads against Culex larvae. Trends Parasitol 2005; 21: 504507.
Teklehaimanot A, Sachs JD, Curtis C. Malaria control needs mass distribution of insecticdal bednets. Lancet 2007; 369: 2143-6.

Received: April 03, 2008

Revised: October 14, 2008

Accepted: October 19, 2008

(C) Dev and Dash; Licensee Bentham Open

This is an open access article licensed under the terms of the Creative Commons Attribution Non-Commercial License (http://creativecommons.org/licenses/by-nc/3.0/) which permits unrestricted, non-commercial use, distribution and reproduction in any medium, provided the work is properly cited. 